\title{
FATIGUE EFFECTS AS MEASURED BY SUGAR CONTENT OF BLOOD
}

\author{
BUFORD J. JOHNSON
}

From the Bureau of Educational Experiments, New York City

The purpose of this investigation was the study of changes in the sugar content of the blood of children as related to different kinds and amounts of activity. Observations of children in the performance of varied activities indicate the need of other criteria of fatigue than diminished capacity or decrease in output in a given activity within a given period of time. In some cases the stimulating factors in the situation lead to a continued output that is relatively good, though the effort expended would indicate the presence of fatigue. In other cases the decrease in output is greater but the assumption that there is greater fatigue present does not seem justified. The intensity of the stimulus to activity is doubtless conditioning the output and interfering with such a form of fatigue test. The tendency to combat the onset of fatigue by exaggerated activity is often noted. This leads to speeding up or spurts and also to a slowing up and increased tension or force in movements. With repetition of the activities at short intervals the behavior of individuals tends to fall into types which emphasize the preceding assumptions.

There is lack of uniformity among investigators concerning the change in sugar content of the blood under continuous working conditions. That a slight but steady increase may occur in the rate at which adrenalin enters the circulation during exercise is held by some writers. Schneider and Havens (1) report an increase in the output of adrenalin with the onset of muscular activity. Cannon (2) holds that adrenalin is secreted under the stimulatory effects of anticipation, enters the blood stream, and

\footnotetext{
${ }^{1}$ A briefer report of this investigation was made at the meeting of the American Psychological Association in Princeton, December, 1921.
} 
increases the functional capacity of muscles. He reports glycosuria after muscular exercise and also after scholarship examinations as evidence of increased sugar content of blood. Stewart and Rogoff (3) found that external manifestations of emotional excitement and presumably, therefore, the visceral concomitants of emotion could be evoked in a perfectly normal manner in animals whose suprarenal glands have been isolated from the central nervous system. Bainbridge (4) reviews the experimental evidence and concludes that the share taken by adrenalin in bringing about the circulatory and other changes taking place during exercise, even when this is carried out under emotional stress, is comparatively small. In a study of the blood of dogs during exercise, Scott and Hastings (5) found that the concentration of sugar falls steadily throughout the work period. Brösamlen and Sterkel (6) assert that the contradictory statements concerning the change in sugar content of the blood that occurs after muscular exercise are due to variations in interval between end of work and determination of blood sugar value. They made determinations before and after exercise, then followed this latter determination by four others made at intervals varying from forty minutes to one hour and twenty minutes. The following data for healthy adults from their study show the irregularity as to decrease or increase in sugar content immediately after exercise.

\begin{tabular}{|c|c|c|c|c|c|c|c|}
\hline nNDTIDE AL & 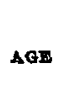 & $\begin{array}{c}\text { TMux OF } \\
\text { Trast } \\
\text { DEYTERMI- } \\
\text { NATION }\end{array}$ & $\begin{array}{c}\text { PIRET } \\
\text { SUGAR } \\
\text { CONTENT }\end{array}$ & 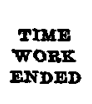 & $\begin{array}{l}\text { TME OF } \\
\text { BECOND } \\
\text { DETRERMI- } \\
\text { NATION }\end{array}$ & $\begin{array}{l}\text { BRCOND } \\
\text { BVGAR } \\
\text { CONTENT }\end{array}$ & VARIATION \\
\hline & & a. $m$. & & a.m. & a. $m$. & & \\
\hline A. & 24 & 7:00 & 0.086 & $7: 40$ & $7: 50$ & 0.082 & -4 \\
\hline B. & 26 & $7: 20$ & 0.093 & $8: 05$ & $8: 20$ & 0.085 & -8 \\
\hline C. & 33 & $7: 05$ & 0.088 & $7: 50$ & $8: 20$ & 0.102 & +14 \\
\hline D. & 27 & $7: 10$ & 0.078 & $7: 50$ & $8: 20$ & 0.074 & -4 \\
\hline $\mathbf{E}$ & 32 & $6: 20$ & 0.096 & $6: 50$ & $7: 00$ & 0.104 & +8 \\
\hline F. & 22 & $6: 20$ & 0.094 & $7: 00$ & $7: 10$ & 0.082 & -12 \\
\hline G. & 18 & $7: 20$ & 0.076 & $8: 05$ & $8: 20$ & 0.087 & +11 \\
\hline H. & 40 & $7: 10$ & 0.082 & $8: 05$ & $8: 20$ & 0.082 & 0 \\
\hline I. & 28 & $7: 10$ & 0.092 & $7: 55$ & $8: 05$ & 0.087 & -5 \\
\hline J. & 21 & $7: 00$ & 0.082 & $7: 50$ & $8: 05$ & 0.084 & +2 \\
\hline
\end{tabular}


They conclude that normally the blood sugar varies little when the body is at rest and fasting, but that fatiguing work by healthy adults generally causes a slight decrease in the sugar content of the blood. The values fluctuate and the lowest value is found at varying intervals after the end of the work. The difference between the rest value and this lowest value amounts on the average to 0.020 . There is then a gradual increase in blood sugar, the maximum increase occurring from one and one half to four hours after the end of the work.

We realize that our data are not conclusive either as to the expected change in sugar content of blood for children after certain kinds of activities or as to the use of blood sugar determinations as a criterion of fatigue. The value of such a method can only be determined by more intensive studies. So few data are available of repeated tests on children under specified conditions that we believe our records are important as a basis for further investigations.

\section{PROCEDURE}

In December, 1920 , eleven subjects were selected as being susceptible to fatigue effects to a greater extent than other children under observation. The selection was made jointly with $\mathrm{Dr}$. Edith Lincoln, whose physical examinations of these children indicated relatively low resistance to fatigue. Our selection was based upon decrease in output as measured by psycho-physical tests in the laboratory and also upon apparent effort expended to make the scores. Only eight subjects, four boys and four girls, were available for the complete experiment with the determinations of sugar content in the blood.

Two series of laboratory tests were devised, one of relatively simple muscular tests, the other involving more complex mental reactions. An attempt was made to establish a standard or reference measure of blood sugar content for each individual for the time of day at which the tests were to be given. Two blood sugar determinations were made with a three weeks interval. These determinations were made by Dr. Liggett Lincoln. In making a determination the procedure was to bring the child up to the laboratory for obtaining a specimen of blood, after which he went 
back to the school room without any work in the psychological laboratory on those days. This was also held to be desirable for adapting the child to such conditions so that we might prevent undue emotional excitation on the days of the test series. These children are familiar with the laboratory and with the examiners; both physician and psychologist have made studies of these children throughout a period of two to three years in each case. Although two children hesitated about the blood test, such experiences as the punctures for blood specimens have not lessened the interest of the children in coming to the laboratory, opportunities for which they solicit. This desire was the strongest incentive during the experiment for one boy who has evinced fear of even slight physical pain. Three weeks elapsed between the time of the second preliminary blood test and the first experimental series. The experiments were made at the same time of day, between 9:30 and 12 in the morning, keeping the order of individuals the same as far as was possible. Breakfast was not omitted. Diet lists showing the food eaten at breakfast had been obtained. The physician considered the breakfasts for all the children fairly standardized as to amount and type of food. More than two hours elapsed between breakfast and test in each case.

A preliminary study was made of the test used in order to determine a series of simple muscular tests in which practice effects could be practically eliminated, and to acquaint the child with the procedure so that he would be at a high level of activity between blood tests. In the spring preceding this study, the target, coördination, tapping, and dynamometer tests were given to a group of children including those to be used in the fatigue experiments. Trials were given daily for nine school days, Saturday and Sunday intervening between the fifth and sixth trials. The curves in figures 1 and 2 show an approximate elimination of practice effects in tapping and coördination. The target records for 30 throws a day continued to show marked fluctuations with little trend toward increased skill in many cases. It was a favorite performance; and the throwing of 100 darts in the fatigue experiment offered an activity adequate to the production of muscular fatigue activity which mere scores do not measure. 


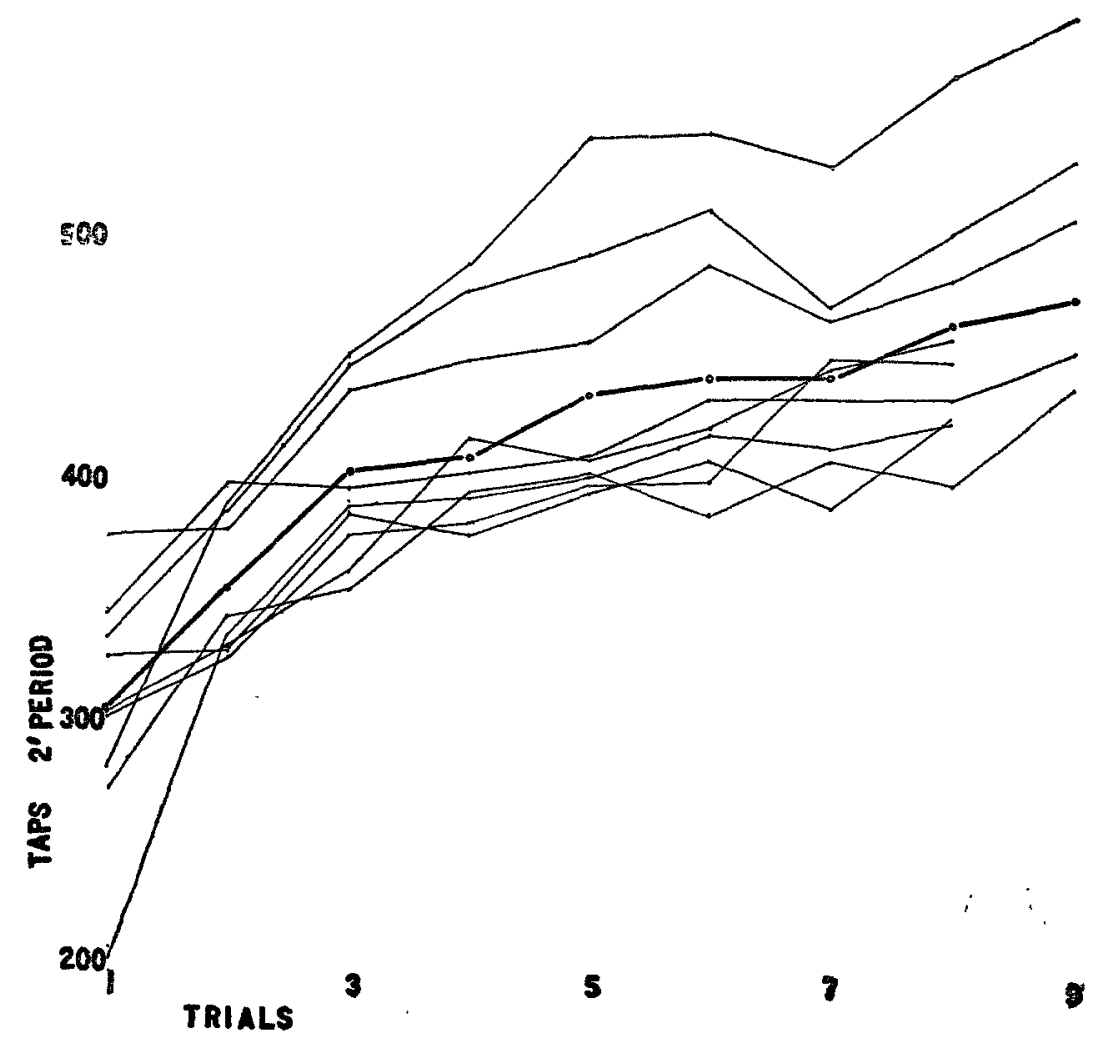

Fig.1. Showing the Practice Erfects in the Tapping Test, Alternate Plate

The light lines are individual curves; the heavy line is a group curve representing the daily average scores.

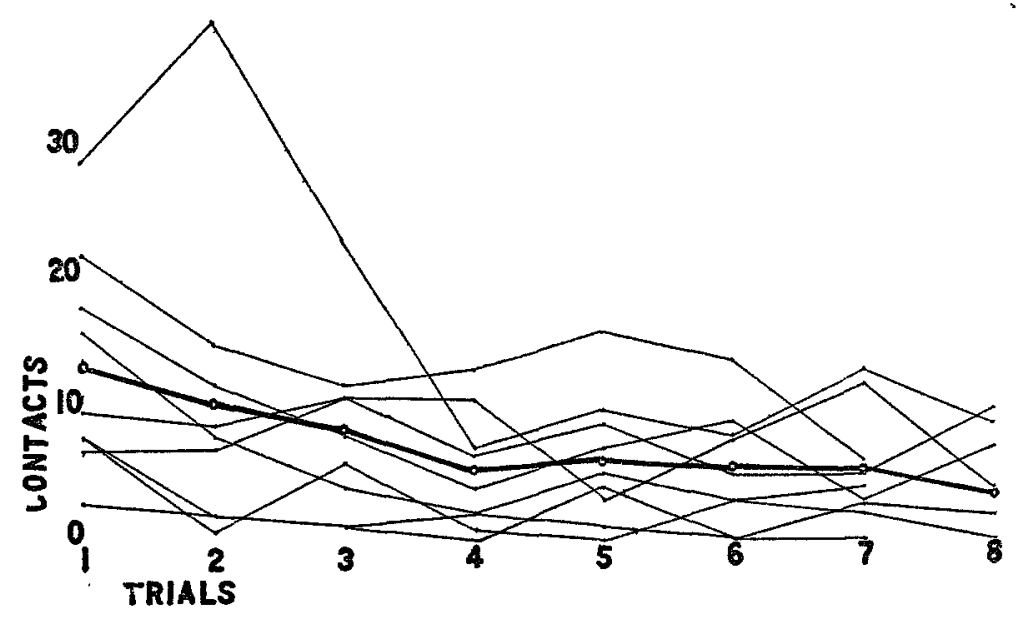

Fig. 2. Showing the Practict Effects in the Coördination Test

The light lines represent individual scores; the heavy line, average scores for the group. 


\section{Series I. Simple muscular tests}

This series included: Target, 100 throws with right hand; dynamometer, 10 trials, left hand; tapping, alternate plate, for two minutes with right hand; tapping, single plate, for two minutes with left hand. They were given in the order listed. The target test was that described by the writer (7) in a former article. The dynamometer and single tapping tests were given according to directions of Woolley and Fischer (8). The alternate tapping plate (9) was so wired that Stoelting make and break counters recorded separately the number of taps for each plate. The child was instructed to strike first one plate and then the other. A few taps were not recorded because the dividing block was struck instead of the plate and also failure to touch the plate was noted even when movement was made approximating contact.

Immediately before the child came into the room for the testing a specimen of blood was obtained by the physician in an adjoining room. The testing required from twenty to twentyfive minutes, varying slightly for individuals because of time variations possible in two tests, the dynamometer and target. Another specimen of blood was obtained immediately after the testing.

In table 1 the sugar content for the preliminary blood tests is shown. We have not been able to get definite standards as to normal sugar content of blood for the ages considered.2 Some of these children vary between the first and second tests as much as $11 \mathrm{mgm}$. per $100 \mathrm{cc}$. while others show as little variation as $1 \mathrm{mgm}$. per $100 \mathrm{cc}$. The average sugar content for the group for the first blood test was 113.57; for the second test, 117; for the third test, 120.125. Of the six individuals considered, two

\footnotetext{
2 Norms vary for different observers. Summaries of these normal values are given by A. Mertz, Archiv. fur Kinderheilkunde, 1920, lxviii, 260. From 2 to 5 years, blood sugar values range from 0.084 to 0.100 ; from 2 to 8 years, 0.080 to 0.120 ; from 2 to 14 years, 0.072 to 0.113 ; from 6 to 14 years, 0.072 to 0.108 . Mertz, A. and Romiger, E., Archiv. fur Kinderheilkunde, 1921, Ixix, 105, give additional data for ages from 7 days to 1 year, 7 days, for which the blood sugar values range from 0.068 to 0.101 with average of 0.081 .
} 
cases show a decrease with variations relatively large. The range of individual variations is from 0 to 26. Only one case shows a decrease in sugar content from the preceding blood test,

TABLE 1

Preliminary blood sugar tests

\begin{tabular}{|c|c|c|c|c|}
\hline & \multirow{2}{*}{$\begin{array}{c}\text { AGI } \\
\text { AT YTRET } \\
\text { BLOOD } \\
\text { TEET }\end{array}$} & \multirow{2}{*}{$\begin{array}{c}\text { HEIGHT } \\
\text { WEIGHT } \\
\text { INDEXX }\end{array}$} & \multicolumn{2}{|c|}{$\begin{array}{l}\text { BLOOD BDGAR } \\
\text { (MGM. PWR 100 CC.) }\end{array}$} \\
\hline & & & $\begin{array}{c}\text { December } \\
18,1920\end{array}$ & $\begin{array}{l}J_{\text {gnuary }} \\
8,1921\end{array}$ \\
\hline & years & & & \\
\hline G. P., girl $\ldots \ldots \ldots \ldots \ldots \ldots \ldots \ldots$ & 6.04 & 0.95 & 0.090 & 0.100 \\
\hline 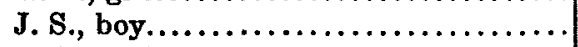 & 7.22 & 0.92 & 0.139 & 0.128 \\
\hline D. P., girl. ....................... & 7.70 & 1.03 & 0.105 & \\
\hline T. F., boy............... & 8.29 & 1.18 & & 0.120 \\
\hline 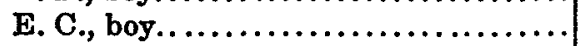 & 8.86 & 1.08 & 0.128 & 0.120 \\
\hline E. R., girl. .................... & 8.87 & 1.07 & 0.112 & 0.116 \\
\hline J. M., boy.................... & 9.14 & 1.18 & 0.110 & 0.115 \\
\hline M. D., girl..................... & 11.01 & 1.23 & 0.111 & 0.120 \\
\hline Avera & & & 113.57 & 117 \\
\hline
\end{tabular}

TABLE 2

Series I. Simple muscular exercise

\begin{tabular}{|c|c|c|c|c|c|c|}
\hline & \multirow{2}{*}{$\begin{array}{l}\text { TARGET } \\
\text { BCORE }\end{array}$} & \multirow{2}{*}{$\begin{array}{c}\text { DTNAMNO- } \\
\text { METER } \\
\text { AVRRARE } \\
\text { BCORE }\end{array}$} & \multicolumn{2}{|c|}{ TAPPENG (2 MINUTTE PERIOD) } & \multicolumn{2}{|c|}{$\begin{array}{l}\text { BLOOD BDEARE } \\
\text { (MGM. PBER } 100 \text { CC.). }\end{array}$} \\
\hline & & & Single plate & $\begin{array}{l}\text { Alternate } \\
\text { plate }\end{array}$ & $\begin{array}{c}\text { Before } \\
\text { exercise }\end{array}$ & $\begin{array}{c}\text { After } \\
\text { érercise }\end{array}$ \\
\hline G. $\mathbf{P}$. & 65 & 9.3 & 526 & 344 & 0.120 & 0.126 \\
\hline J.S. & 246 & 8.2 & 429 & 268 & 0.130 & 0.125 \\
\hline D. P. & 82 & 11.0 & 517 & 424 & 0.102 & 0.110 \\
\hline T. F. & 222 & 14.1 & 286 & 258 & 0.126 & 0.152 \\
\hline E. C. & 117 & 11.6 & 591 & 446 & 0.120 & 0.124 \\
\hline E. R. & 140 & 7.7 & 429 & 361 & 0.090 & 0.120 \\
\hline J. M. & 342 & 12.6 & 510 & 423 & 0.128 & 0.130 \\
\hline M. D. & 169 & 12.3 & 411 & 510 & 0.145 & 0.142 \\
\hline \multicolumn{5}{|c|}{ Average............. } & 120.125 & 128.63 \\
\hline
\end{tabular}

but this is the largest variation found. Another case shows an increase of 25 . These two individuals seem especially susceptible to fatigue and are also easily stimulated to emotional responses. These percentages of blood sugar are high as com- 
pared with values usually given for children and adults. They exceed any blood sugar given by Brösamlen and Sterkel (10) for healthy adults. When we average the three blood sugars preceding series I for each individual and get the group average we have 117.89 with standard deviation of 8.44 . The group average after the tests was 128.63 with a standard deviation of 12.142. The difference between this and the average of the blood sugar determinations preceding the testing is 8.5 which equals 1.78 times the probable error. Correlation of the blood sugar ratings immediately before series I with those immediately after gives $r=0.53$. There is evident a slight increase in blood sugars after the simple muscular exercise.

TABLE 3

\begin{tabular}{|c|c|c|c|c|c|c|c|c|c|c|c|c|}
\hline & \multicolumn{3}{|c|}{$\begin{array}{c}\text { DYNAMOMETER } \\
\text { AVERAGES } \\
\text { FOR RIGHT HAND }\end{array}$} & \multirow{3}{*}{$\begin{array}{c}\text { ADDING } \\
\text { MA- } \\
\text { CHINE }\end{array}$} & \multicolumn{6}{|c|}{ TAPPING-ADPARATE PLATRS } & \multicolumn{2}{|c|}{$\begin{array}{l}\text { BLOOD SUGAB } \\
\text { (MGM PEB } \\
100 \mathrm{CC} .)\end{array}$} \\
\hline & \multirow{2}{*}{ 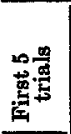 } & \multirow{2}{*}{ 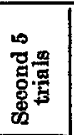 } & \multirow{2}{*}{ 串量 } & & \multicolumn{3}{|c|}{ Right hand } & \multicolumn{3}{|c|}{ Left hand } & \multirow{2}{*}{ 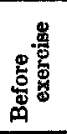 } & \multirow{2}{*}{ 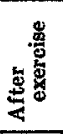 } \\
\hline & & & & & (1) & (2) & (3) & (1) & (2) & (3) & & \\
\hline T. F. & 22.2 & 19.2 & 20.7 & & 472 & 450 & 522 & 445 & 521 & 441 & 115 & 120 \\
\hline E. R. & 13.2 & 13.4 & 12.8 & 56 & $*$ & 477 & 378 & $*$ & 354 & 275 & 112 & 125 \\
\hline M. D. & 19.4 & 22.0 & 18.0 & 66 & 494 & 435 & 436 & 436 & 422 & 369 & 116 & 118 \\
\hline
\end{tabular}

* Wire was loose and record lost for first trials.

Two of these children showed such a large amount of sugar and one showed so great an increase in sugar content that a repetition of muscular tests was made. Blood sugar specimens were again obtained immediately preceding and following the tests. The tests given were tapping, dynamometer and exercise upon an adding machine. The tapping was done with both hands on separate plates with the board so wired that records were separately kept for each hand. Three trials were given with thirty second intervals. With the dynamometer fifteen trials were made with the right hand. The adding machine was arranged so that 1 was printed each time the handle was pushed back. The child was instructed to do this as rapidly as possible. It was 
continued for one minute. The sum printed was recorded as the score.

The sugar content for two of these cases was not nearly so high before these activities as in the first series and there is but a slight change after exercise. The third case has a sugar content higher by 22 than that preceding the first muscular tests but does not show so great an increase after exercise. though the blood sugar then is the highest for this child during the experiment. A slight increase in blood sugar after exercise is found for all three subjects.

\section{Series II}

The second series for producing fatigue from more complex reactions involving little muscular exercise was given May 17, 1921. The same procedure was followed in obtaining blood specimens both before and after the activities in the laboratory. The tests were given in the following order: coördination, discrimination, memory for digits, and substitution. In the coördination test (fig. 3 ) the child was instructed to trace a path without touching the sides, but in tracing a given segment to make a stroke of the pencil to the beat of the metronome. This was set at one hundred beats per minute. An actual record made during the experiment is shown in figure 3. Number of contacts and time were recorded.

The discrimination test involved the sorting of fifty-two ordinary playing cards. In the center of each card was cut a diamond-shaped hole. The holes were so cut that in thirteen cards the long axis of the diamond was lengthwise the card; in thirteen cards it was crosswise the card; in thirteen cards it extended in the diagonal from the upper right to the lower left; in the remaining cards from the upper left to the lower right. A wooden receptacle of five open stalls was clamped to a table under an adjustable screen so that the stalls and cards could not be seen. The cards, carefully shuffled, were placed in the end stall at the left. The subject was instructed to take from the top of the pack one card at a time with the left hand and while holding it in this hand to run the thumb and forefinger of the other hand around 
Th.D. 5/17/21 1 min tsece.

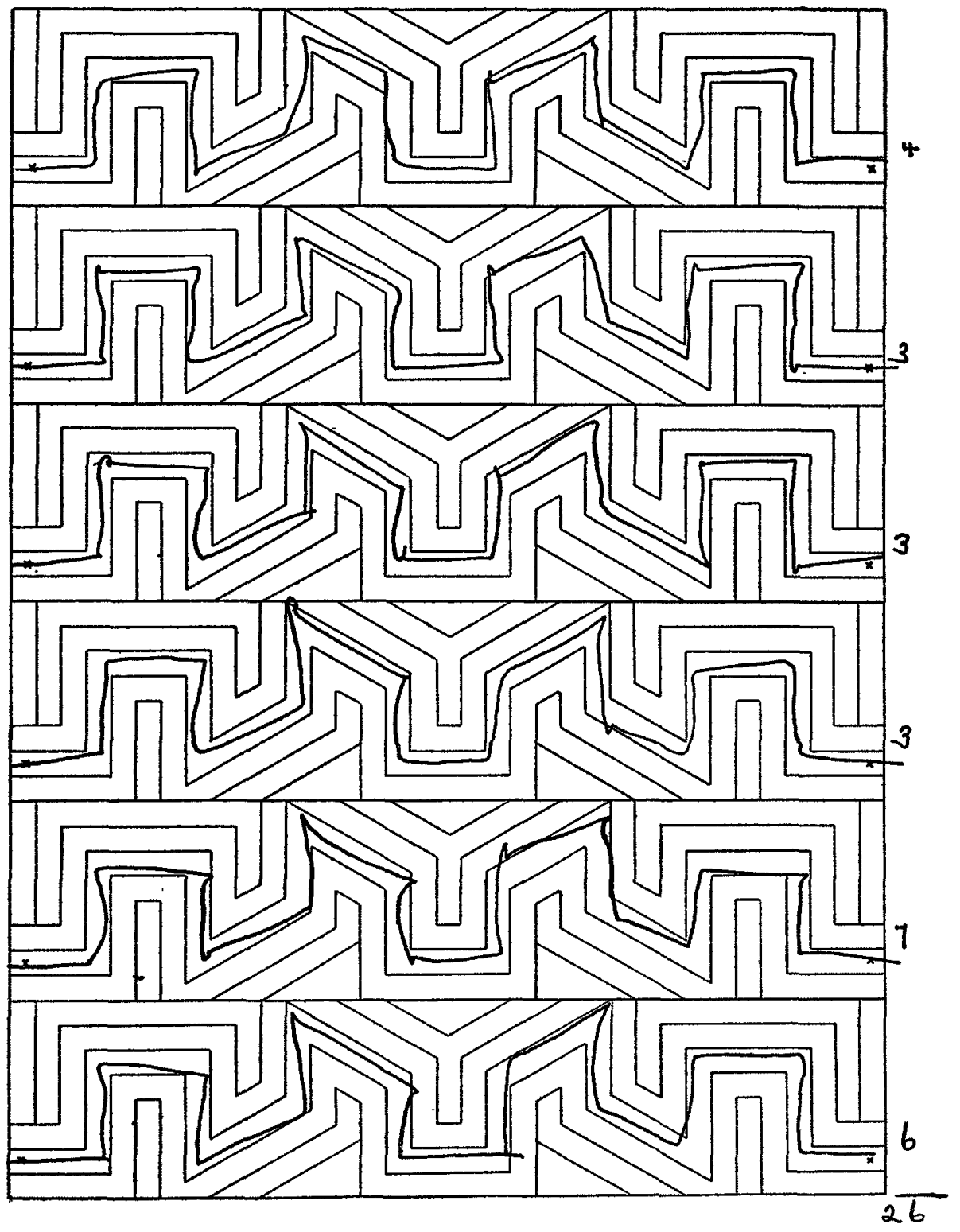

Fig. 3. An Actual Recond in the Coöhdination Thet 
the edge of the hole. He was then to place the card in that stall designated for cards with the diamond in that position. The sorting continued in this manner until all the cards had been distributed. The record sheet in figure 4 shows the type of errors made.

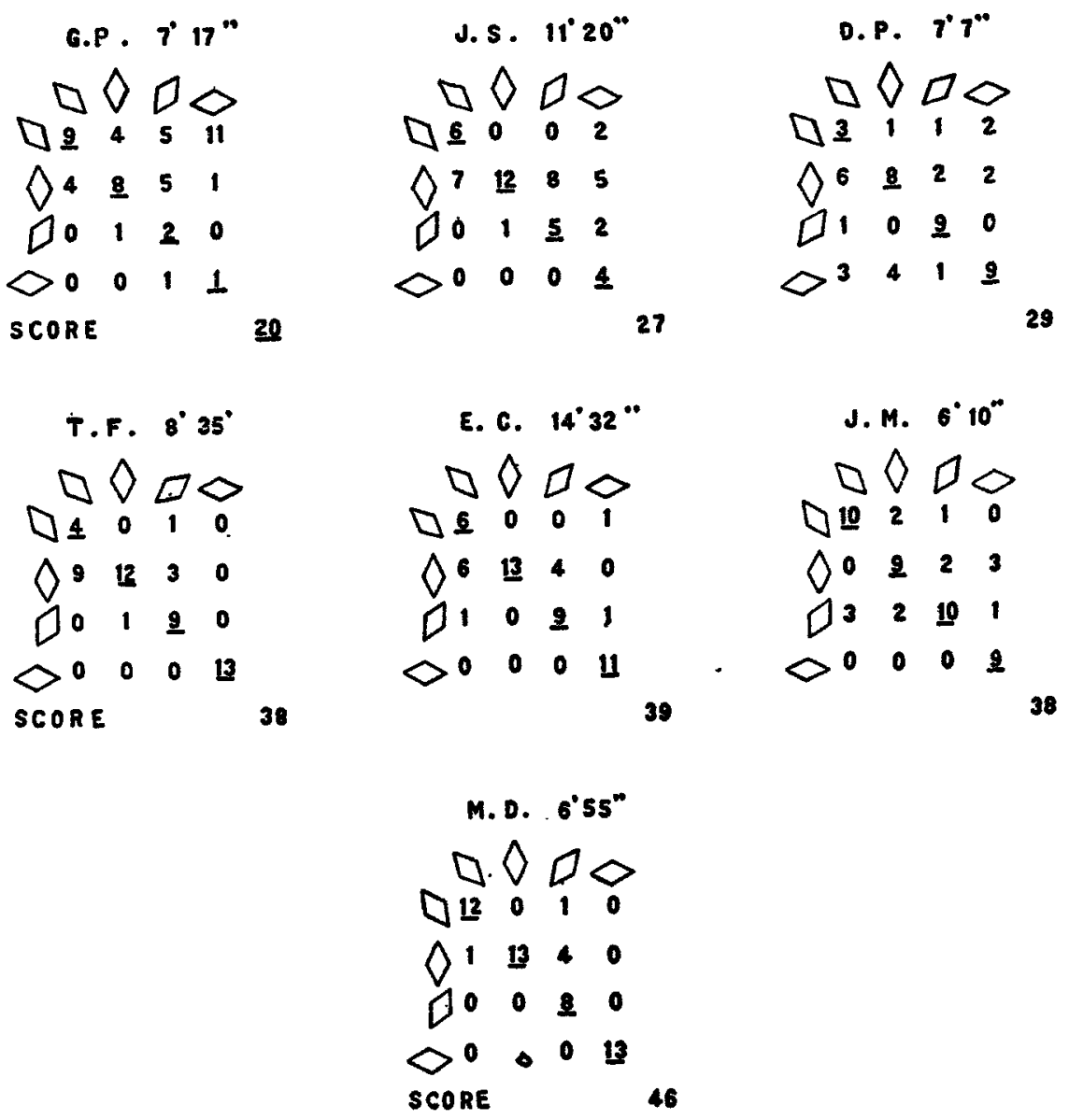

Fia. 4. Ricord of Trme and Placements in the Discrimination Test

In the test of memory for digits the procedure followed was that described in the monograph by Woolley and Fischer (11) previously mentioned. The substitution blank used was a symbol form devised by Dunlap. A record made by the youngest 


$$
\begin{aligned}
& \text { If } P \text { 5/17/21 } 4 \text { men ibsee Correct }
\end{aligned}
$$

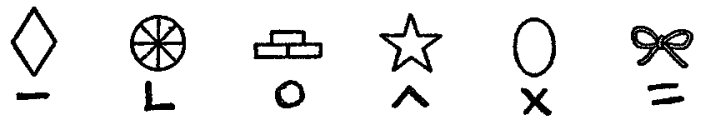

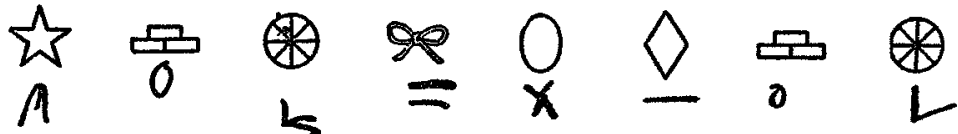

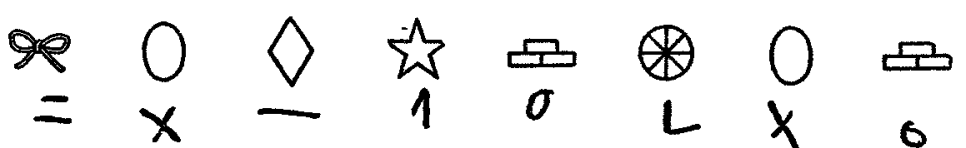

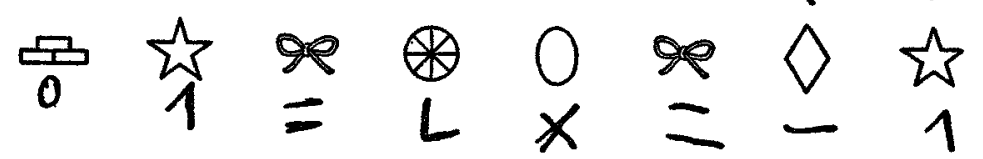

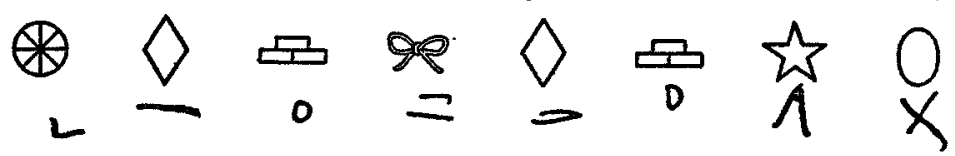

资电方

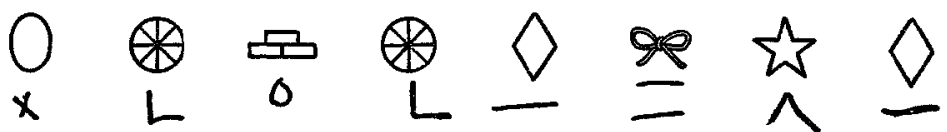

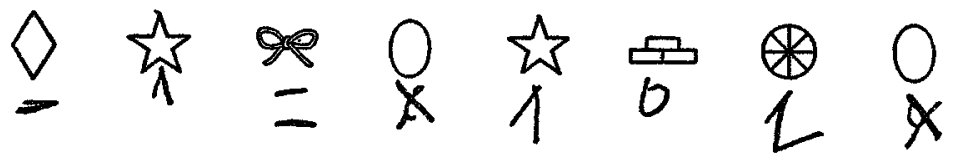

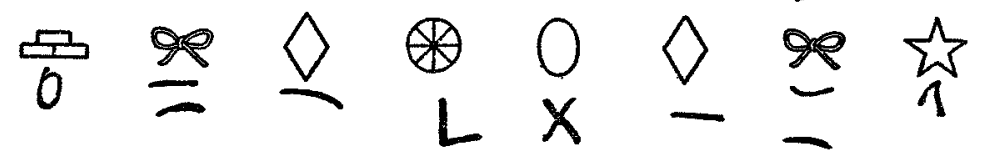

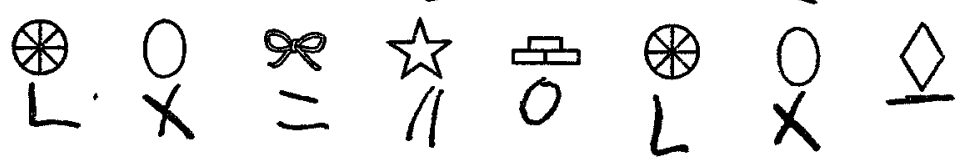

Fig. 5. Regord Made by the Yodngest Child in tere Substitution Test 
child is shown in figure 5. It was required that symbols be substituted for symbols.

TABLE 4

Series II, May 17, 1921

\begin{tabular}{|c|c|c|c|c|c|c|c|c|}
\hline & \multicolumn{2}{|c|}{$\begin{array}{l}\text { MOTOR COORDINATION } \\
\text { TEST }\end{array}$} & \multicolumn{2}{|c|}{ FORM DISCRIMINATION } & \multicolumn{2}{|c|}{$\begin{array}{l}\text { MEMORY FOR } \\
\text { DIGITS }\end{array}$} & \multicolumn{2}{|c|}{$\begin{array}{l}\text { BUBSTYTUTYON } \\
\text { (FORM 1) }\end{array}$} \\
\hline & Time & $\begin{array}{c}\text { Number of } \\
\text { contacts }\end{array}$ & Time & Score & Span & Score & Time & Errors \\
\hline G.P. & $1^{\prime} 26^{\prime \prime}$ & 38 & $7^{\prime} 17^{\prime \prime}$ & 20 & 5 & 40 & $4^{\prime} 16^{\prime \prime}$ & 0 \\
\hline J. S. & $1^{\prime} 11^{\prime \prime}$ & 36 & $11^{\prime} 20^{\prime \prime}$ & 27 & 6 & 66 & $4^{\prime} 10^{\prime \prime}$ & 0 \\
\hline D. P. & $1^{\prime} 30^{\prime \prime}$ & 20 & $7^{\prime} 7^{\prime \prime}$ & 29 & 7 & 100 & $3^{\prime} 4^{\prime \prime}$ & 1 \\
\hline T. F. & $1^{\prime} 29^{\prime \prime}$ & 42 & $8^{\prime} 35^{\prime \prime}$ & 38 & 4 & 31 & $2^{\prime} 43^{\prime \prime}$ & 0 \\
\hline E. C. & $1^{\prime} 10^{\prime \prime}$ & 38 & $14^{\prime} 32^{\prime \prime}$ & 39 & 9 & 175 & $3^{\prime} 18^{\prime \prime}$ & 0 \\
\hline J. M. & $1^{\prime} 20^{\prime \prime}$ & 14 & $6^{\prime} 10^{\prime \prime}$ & 38 & 9 & 164 & $3^{\prime} 4^{\prime \prime}$ & 2 \\
\hline M. D. & $1^{\prime} 4^{\prime \prime}$ & 26 & $6^{\prime} 55^{\prime \prime}$ & 46 & 7 & 101 & $2^{\prime} 28^{\prime \prime}$ & 0 \\
\hline
\end{tabular}

TABLE 5

Series II. Blood sugar, blood pressure and urinalysis, May 17, 1921

\begin{tabular}{|c|c|c|c|c|c|c|c|c|}
\hline & \multicolumn{2}{|c|}{$\begin{array}{l}\text { BLOOD QUGAR } \\
\text { (MGM. PTBR } \\
100 \text { CC.) }\end{array}$} & \multicolumn{2}{|c|}{$\begin{array}{l}\text { BLODD } \\
\text { PRESSURE }\end{array}$} & \multirow{2}{*}{$\begin{array}{c}\text { URINALYSIS } \\
\text { AFTTER } \\
\text { WXFRCISE } \\
\text { FOR SUGAR }\end{array}$} & \multicolumn{3}{|c|}{ PREVIOUS BLOOD FEEESURES } \\
\hline & $\begin{array}{l}\text { Before } \\
\text { exereise }\end{array}$ & $\begin{array}{l}\text { After } \\
\text { exercise }\end{array}$ & $\begin{array}{l}\text { Before } \\
\text { exercise }\end{array}$ & $\begin{array}{c}\text { After } \\
\text { exercise }\end{array}$ & & $1918-10$ & $1919-20$ & $1920-21$ \\
\hline G. P. & 85 & 89 & $\frac{88}{60}$ & $\frac{102}{62}$ & None & $\frac{78}{58} \quad \frac{78}{56}$ & $\frac{92}{62}$ & $\frac{90}{70}$ \\
\hline J.S. & 90 & 88 & $\frac{108}{74}$ & $\frac{90}{68}$ & None & & $\frac{90}{58}$ & $\frac{94}{72}$ \\
\hline D. P. & 81 & 84 & $\frac{96}{72}$ & $\frac{96}{68}$ & None & $\frac{90}{58} \quad \frac{92}{60}$ & $\frac{88}{62} \quad \frac{90}{56}$ & $\frac{92}{68}$ \\
\hline T. F. & 88 & 90 & $\frac{102}{72}$ & $\frac{98}{76}$ & None & $\frac{106}{66} \quad \frac{110}{66}$ & $\frac{96}{58}$ & $\frac{104}{76}$ \\
\hline E. C. & 92 & 85 & $\frac{110}{76}$ & $\frac{110}{72}$ & None & & & $\frac{98}{76}$ \\
\hline J. M. & 100 & 102 & $\frac{96}{64}$ & $\frac{100}{66}$ & None & $\frac{78}{66} \quad \frac{82}{66}$ & $\frac{90}{64} \quad \frac{90}{64}$ & $\frac{98}{76}$ \\
\hline M.D. & 101 & 110 & $\frac{122}{78}$ & $\frac{98}{78}$ & None & $\frac{88}{64} \quad \frac{86}{64}$ & $\frac{88}{62}$ & $\frac{106}{78}$ \\
\hline
\end{tabular}


In table 5 it is shown that the sugar content immediately preceding these tests was lower in each case than in previous determinations. The variation after exercise is less than that between any other two measures except in two cases.

We have no explanation for the fall in sugar content unless it is due to seasonal variation, ${ }^{3}$ such as reported by Strouse (12). The blood pressure and urinalysis add little to the interpretations. It might be argued that emotional excitation in preceding determinations influenced the sugar content. That a child should be so much affected in four or six blood tests and not in the next can not be assumed. This fall is noted for the children who had supplementary tests and for those who did not. The preceding activities and breakfasts were approximately the same as in preceding tests.

\section{DISCUSSION AND SUMMARY}

The range in chronological age is such as to invalidate direct comparisons of output and changes in sugar content. We give the records to indicate the actual work done by each individual. In the preliminary study of tests for use in this investigation we found a decrease in tapping scores for the fourth period of thirty seconds as compared with the first period. The graphs in figure 6 show this diminished output for each of the nine practice periods. While the decrease fluctuates from day to day, there is no tendency towards a lessening of this difference with increasing practice. Individuals vary as to the period in which least capacity is shown. If a higher level of efficiency is maintained for the first two periods there often results a marked decrease in the third period, with perhaps a slight increase for the fourth or final period. Others show a gradual diminution in capacity from the first to the final period. The fluctuations in the group curves II, III, and IV are probably due to these individual differences.

- Strouse found that the average blood sugar readings were higher in the cooler part of the year. Daily variations of blood sugar percentage occurred in five normal persons. These variations seem to depend on changes in the weather. 


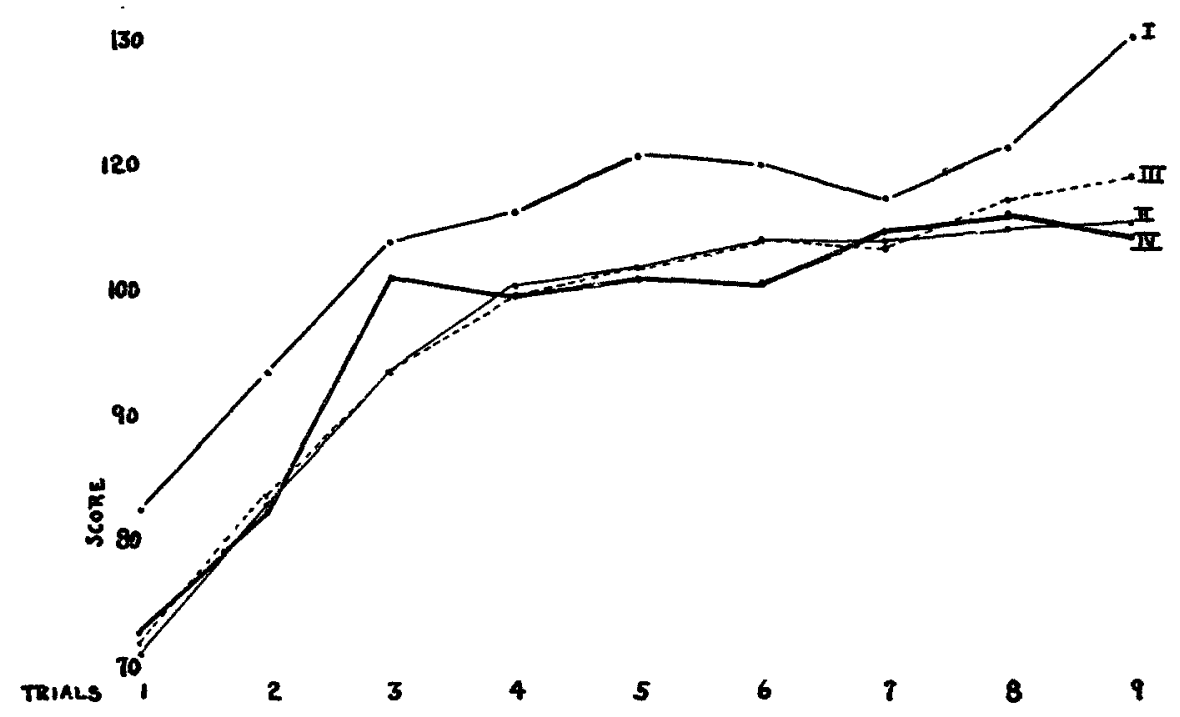

Fig.6. Showing the Daily Scores for Thirty-Second Periods in the Tapping Test, Alternate Plate, for Nine Children

I, Average daily score for first period; II, for second period; III, for third period; IV, for fourth period.

TABLE 6

Individual variations

\begin{tabular}{|c|c|c|c|c|c|c|}
\hline & $\begin{array}{l}\text { FIRSR AND } \\
\text { BECOND } \\
\text { PRIRLAMI- } \\
\text { NARY }\end{array}$ & $\begin{array}{l}\text { BHCOND } \\
\text { PRELIMI- } \\
\text { NARY ANT } \\
\text { BRFORE } \\
\text { BREIES I }\end{array}$ & $\begin{array}{c}\text { BEFORD } \\
\text { AND ATTYR } \\
\text { BERIRB I }\end{array}$ & $\begin{array}{c}\text { AFTER } \\
\text { ERRIES I } \\
\text { ANYD } \\
\text { BXYFORI } \\
\text { BERIES II }\end{array}$ & $\begin{array}{c}\text { BEFORR } \\
\text { AND AFTRER } \\
\text { SERIER II }\end{array}$ & $\begin{array}{l}\text { AVERAGE } \\
\text { DEVIATION }\end{array}$ \\
\hline G.P........... & 10 & 10 & 6 & -41 & 4 & 14.2 \\
\hline J. S............. & -11 & 2 & -5 & -35 & -2 & 11.0 \\
\hline D.P............ & & & 8 & -29 & $\mathbf{3}$ & 13.3 \\
\hline T. F............ & & 6 & 26 & -64 & 2 & 24.5 \\
\hline E. C........... & -8 & 0 & 4 & -32 & -7 & 10.2 \\
\hline E. R........... & 4 & -26 & 30 & & & \\
\hline Ј. М........... & 5 & 13 & 2 & -30 & 2 & 10.4 \\
\hline 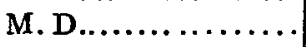 & 9 & 25 & -3 & -41 & 9 & 17.4 \\
\hline Average........... & 7.83 & 11.71 & 10.5 & 38.85 & 4.14 & 14.43 \\
\hline
\end{tabular}


The individual variations shown in table 6 indicate little stability in blood sugar for a given individual under the conditions of the experiment. We find that a child may show a relatively high sugar content before exercise and either slight or marked increase after exercise. Relatively low content of sugar is also found preceding exercise with a rise of as much as 0.030 after exercise. In some cases a slight decrease is found. We do not know whether such variations are due to a slow rise or to a slow fall in sugar content; to the amount and kind of activity; or to affective factors. Individual E. C., who has been characterized as fearful of slight physical pain and with whom the physician reasoned for some minutes before securing assent to the blood test preceding series I, shows the least average variation. The change in sugar content as shown by determinations made on the same day preceding and after exercise is less on the average than the total group variation. This group average is heavily weighted by the variation in blood sugars obtained April 19, 1921, and May 17, 1921. This we attribute to elevation of temperature. The weather conditions on the days of the experiment were as follows:

\begin{tabular}{|c|c|c|c|c|c|}
\hline & $\begin{array}{c}\text { DECEM- } \\
\text { BER 18, } \\
1920\end{array}$ & $\begin{array}{l}\text { JANU- } \\
\text { ARY 8, } \\
1921\end{array}$ & $\begin{array}{c}\text { JANU:- } \\
\text { ARY 26, } \\
1921\end{array}$ & $\underset{1921}{\text { APRR }}$ & $\underset{1921}{\operatorname{MAT} 17}$ \\
\hline Temperature at 9 a.m. F............ & 29.0 & 39.0 & 12.0 & 39.0 & 48.0 \\
\hline Humidity at 8 a.m...... & 0.66 & 0.96 & 0.52 & 0.90 & 0.65 \\
\hline Barometer at 8 a.m..... & 29.71 & 29.72 & 30.45 & 29.92 & 30.22 \\
\hline
\end{tabular}

The effects of this seasonal change in sugar content as related to the optimal schedule of activities for school children merits investigation. If we exclude this factor, the change in sugar content for series I, simple muscular exercise, appears more significant. Two children stand out from the group with regard to the internal conditions under which work is performed. In the preliminary practice series for tapping test, alternate plate, the relative capacity of these two children is shown by the following results. 


\begin{tabular}{|c|c|c|c|}
\hline & GROUP & m. R. & T. r. \\
\hline Average total output... & 3769.33 & 3377.00 & 2552.00 \\
\hline Average daily output........ & 418.80 & 375.00 & 364.00 \\
\hline Average for 1st 30 outputs.......... & 113.79 & 99.44 & 98.00 \\
\hline Average for 4 th 30 outputs............... & 100.78 & 92.55 & 92.71 \\
\hline
\end{tabular}

It is evident that the stimulating effects of environmental factors are widely different for different children.

Conclusions as to the influence of different kinds and amounts of activities upon the sugar content of the blood would be unwarranted by our data. We believe that they indicate a method of investigation that may clarify the concepts of fatigue and lead to a reformulation of the factors involved in fatigue effects. It seems essential that we make successive determinations throughout a stated period of the day and over a period of time sufficiently long for us to know what the normal changes are for the individuals under observation. Determinations should be made at short intervals preceding and following specific activities which vary in complexity and in motivation.

\section{REFERENCES}

(1) SchNomer, E. C., AND HAvens, L. C.: Changes in the blood after muscular activity and during training. Amer. Jour. Physiol., 1915, xxxvi, 256.

(2) CanNoN, W. B.: Bodily changes in pain, hunger, fear and rage, 211.

(3) Stewart, G. N.; AND Rogofr, J. M.: Further observation's of relation of adrenals to certain experimental hyperglycemias. Amer. Jour. Physiol., 1920, lvii, 376.

(4) BannBridge, F. A.: The physiology of muscular exercise, 128-138.

(5) Scotr, E. L., AND HAstivgs, A. B.: A study of the sugar and oxygen relationships in the blood of dogs during exercise. Proc. Soc. Exper. Biol. and Med., 1920, xvii, 120-122.

(6) BrösamLen, O., aNd Sterkel, H.: Der Einfluss von Muskelarbeit auf den Blutzuckergehalt. Deutsches Arch. fur Klin. Med., 1919, exxx, 360363, 371-372.

(7) JoHnson, B.: Practice effects in a target test-a comparative study of groups varying in intelligence. Psychol. Rev., 1919, xxvi, 300-316.

(8)' WoolLex, H. T., AND Fischer, C. R.: Mental and physical measurements of working children, 52,75 .

(9) DUNLAP, K.: Improved form of steadiness tester and tapping plate. Jour. of Exper. Psychol. 1921, vol. IV, 430-432.

(10) Brösamlen, O., and StTerker, H.: Op. cit., p. 360-363.

(11) Woolley, H. T., and Fischer, C. R.: Op. cit., p. 123.

(12) Strousw, S.: Some variations in normal blood sugar. Archiv. Int. Med., 1920, xxvi, 758. 